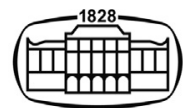

AKADÉMIAI KIADÓ

Journal of Behavioral

Addictions

10 (2021) 3, 811-826

DOI:

10.1556/2006.2021.00048

(c) 2021 The Author(s)

\section{FULL-LENGTH REPORT}

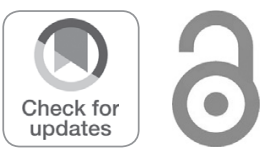

\title{
Understanding juveniles' problematic smartphone use and related influencing factors: A network perspective
}

\author{
SHUNSEN HUANG ${ }^{1}$ (1), XIAOXIONG LAI ${ }^{1}$ (1), YAJUN LI ${ }^{2}$, \\ YUHAN LUO ${ }^{1,3}$ and YUN WANG ${ }^{1 *}$
}

\author{
${ }^{1}$ State Key Laboratory of Cognitive Neuroscience and Learning, Beijing Normal University, Beijing, \\ China \\ ${ }^{2}$ School of Education, Henan University, Kaifeng, China \\ ${ }^{3}$ Collaborative Innovation Centre of Assessment for Basic Education Quality, Beijing Normal \\ University, Beijing, China
}

Received: March 21, 2021 • Revised manuscript received: May 26, 2021; July 2, 2021 • Accepted: July 3, 2021

Published online: August 18, 2021

\begin{abstract}
Background and aims: To understand the interaction between problematic smartphone use (PSU) and related influencing factors (individual variables, family environment, and school environment) and to determine the most influential factors affecting the use of smartphones by juveniles to implement effective interventions in the future. Methods: A total of 3,442 children and adolescents (3,248 actual participants (males $=1,638$, average age $=12.27 \pm 2.36$ ) ) were included in the study. This study measured juveniles' PSU and its influencing factors: individual variables (4 factors), family environments (13 factors), and school environments (5 factors). This study employed a network analysis approach for data assessment. Results: This study found that there were several central influencing factors (such as self-control ability, loss of control, parent-child relationship, and peer attitudes towards smartphone use) and bridge factors (such as peer attitudes towards smartphone use, peer pressure for smartphone use, and fear of missing out). Discussion and conclusions: Juveniles' PSU included several core symptoms and critical influencing factors. Intervention based on these factors may be effective, timely, and inexpensive.
\end{abstract}

\section{KEYWORDS}

problematic smartphone use, network theory of mental disorder, ecological system theory, network analysis, juvenile

\section{INTRODUCTION}

With the advent of the media age, smartphones are becoming increasingly popular among ordinary people due to their various functions, such as surfing on the Internet, socializing with others, facilitating work, and promoting leisure. Taking the Chinese population as an example, the CNNIC's report indicated that as of December 2018, 817 million people had access to the Internet through mobile phones, accounting for $98.6 \%$ of Chinese netizens (CNNIC, 2019). Although smartphones have many advantages, societies (e.g., researchers) have discussed the phenomenon of problematic smartphone use, which can be defined as compulsive and dependent use that interferes with a user's daily life (Horwood \& Anglim, 2018). Many researchers have defined this phenomenon as "smartphone addiction" (Herrero et al., 2017; Kim, Lee, Lee, Nam, \& Chung, 2014; Kwon et al., 2013; Wang et al., 2017) or "cell-phone addiction" (see Gutiérrez, de Fonseca, \& Rubio, 2016), while we use the term "problematic smartphone use" (PSU) due to the recently debated topic about the terminology of this phenomenon (Billieux, Maurage, Lopez-Fernandez, Kuss, \& Griffiths, 2015; Panova \& Carbonell, 2018). 
Indeed, PSU is related to a series of negative consequences, such as emotional health problems, physical health problems, decreased professional performance and social performance, and dangerous technology use (Busch \& Mccarthy, 2020). For some time, researchers have been attempting to identify antecedents of problematic smartphone use because they believe that future interventions can correct these problematic behaviors by focusing on these factors (Busch \& Mccarthy, 2020). However, previous studies have rarely considered the interaction between PSU and antecedent factors, as some antecedents can also be the outcomes of PSU (e.g., loneliness, self-control issues (Busch \& Mccarthy, 2020). Conventional research in this field regards PSU as an independent variable that directly or indirectly influences other variables (Choi, Choi, \& Kim, 2017; Demirci, Akgönül, \& Akpinar, 2015; Elhai, Levine, Dvorak, \& Hall, 2016; Karsay, Schmuck, Matthes, \& Stevic, 2019; Škařupová, Ólafsson, \& Blinka, 2016; YoungJin \& Kyunghee, 2018) or considers PSU an outcome of indirect or direct influences of other variables (Cho, Kim, \& Park, 2017; Elhai et al., 2016, 2018; Kim et al., 2016, 2018, 2019; Kwak, Kim, \& Yoon, 2018; Wang et al., 2017, 2019).

Network analysis methods can help fill this gap by putting all factors or symptoms into an interconnected network (Borsboom, 2017; Borsboom \& Cramer, 2013). Few researchers have attempted to explore the interactions of PSU. Rather, they have mainly focused on the inner symptoms of PSU (Andrade, Scatena, Martins, et al., 2020; Huang, Lai, Xue, Zhang, \& Wang, 2020). For example, researchers have explored the central symptoms of PSU (Huang et al., 2020) or the validation of the smartphone addiction scale (Andrade, Kim, et al., 2020; Andrade, Scatena, Martins, et al., 2020) from a network analysis perspective. In addition, several researchers have explored the interaction between Internet addiction and psychological symptoms from a network aspect (Andrade, Scatena, Bedendo, et al., 2020). However, although previous researchers have explored this area, they have not addressed the interaction between PSU and related factors from a more macro network perspective. Therefore, based on the network theory of mental disorder (NTMD) (Borsboom, 2017), ecological system theory (EST) (Bronfenbrenner, 1979), and ecological techno-subsystem theory (ETST) (Johnson \& Puplampu, 2008), this study aimed to examine the interactions within antecedents and interactions between antecedents and PSU to try to determine the most influential factors impacting youth PSU. Our primary research objectives were as follows. First, we illustrated why other antecedents should be summed to study PSU from the perspective of ecological system theory. Second, we used the network theory of mental disorders to explain the importance of considering the bidirectional relationship between antecedents and PSU. Third, we discussed the combination of these theories and implemented a network approach to analyze the interaction between PSU and its antecedents, which were chosen based on robust evidence from previous research.

\section{Theoretical construct}

Ecological system theory (EST) and ecological techno-subsystem theory (ETST). The ecological system theory developed by Bronfenbrenner (1979, 1993) claims that individuals are surrounded by 4 nested systems or environments: microsystems, mesosystems, exosystems, and macrosystems. In this theory, individuals are in the center, and subsystems are nested (e.g., individuals are nested by microsystems, and microsystems are nested by exosystems). In this study, we focused only on microsystems and mesosystems because of their direct influences on individuals and interaction between variables. Microsystems refer to a pattern of activities, roles, and interpersonal relationships experienced directly by the developing person in a given setting (e.g., school environments, family environments), and exosystems refer to the interconnections between various microsystems (Bronfenbrenner, 1979). Ecological systems emphasize functional links or interactions within microsystems and interactions between different microsystems (Vandell, Larson, Mahoney, \& Watts, 2015). Additionally, Johnson and Puplampu (2008) proposed ecological techno-subsystem theory (ETST) based on EST and ubiquitous Internet use in modern life. The ETST claims that the techno-subsystem is a microsystem that includes child interactions with both human (e.g., communicator) and nonhuman (e.g., hardware) elements of information, communication, and recreational digital technologies. Therefore, the Internet can affect juveniles' microsystems (e.g., home, school, and community).

Taking juveniles' problematic smartphone use as an example, peer PSU may influence juveniles' PSU, which in turn influences peer PSU. This is known as the peer contagion effect (Dishion \& Tipsord, 2011), which is a process of interactions among individuals and peers that includes behaviors and emotions that potentially undermine a person's development or cause harm to others. In addition, parents' PSU (family microsystem) may influence juveniles' PSU, which then exerts an influence on peer behaviors (school microsystem), such as friendship quality and peer PSU. This phenomenon is described as a spillover effect (Ko, 2012; Peng, 2017; Sears, Repetti, Reynolds, Robles, \& Krull, 2016), which suggests that a stressful consequence in one context (e.g., marital conflict) has a direct impact on an individual's emotions or behaviors in another context. As mentioned above, although previous research on PSU antecedents has focused on the linkages within microsystems and linkages between microsystems, these studies tested only single or unidirectional paths between variables, ignoring the interactions or feedback effects between variables. This suggests that we should explore youths' PSU and its related factors from a whole and interconnected perspective.

The network theory of mental disorders (NTMD). The representative view of this theory is that if a set of coupled symptom sets are close to each other in the network structure, they will tend to be synchronized. Mental disorders then arise when groups of tightly coupled symptoms actively 
maintain each other, leading to a cluster of psychopathological symptoms that becomes self-sustaining (Borsboom, 2017). Borsboom (2017) indicated that if an (experimental or natural) intervention changed the state of one symptom, this would change the probability distributions of the other symptoms. Therefore, researchers have developed a network analysis method to determine the functional roles and importance of specific symptoms in maintaining disorders (Borsboom, 2017; Borsboom \& Cramer, 2013; Bringmann et al., 2013), e.g., to determine the core symptoms in disordered networks, which will benefit the treatment and intervention of disorders (Beard et al., 2016; Borsboom \& Cramer, 2013; Elliott, Jones, \& Schmidt, 2020; Levinson et al., 2017; Soares, Santiago, Biazevic, Michel-Crosato, \& Jamieson, 2020; Soares, Santiago, Michel-Crosato, \& Jamieson, 2020). Many researchers have used the network approach (network analysis) to analyze the symptoms of depressive disorders, autism spectrum disorder, posttraumatic stress disorder, and personality traits (Bringmann \& Eronen, 2018). The network approach (Borsboom \& Cramer, 2013), which appeared earlier than the network theory proposed by Borsboom (2017), can be regarded as a method that depicts a network graph of interconnected nodes with edges, whose thickness represents the intensity of the connection. Therefore, the network can tell the relative position of one node to all other nodes, namely, the most core or central node in the whole network (Beard et al., 2016; Borsboom \& Cramer, 2013; Bringmann et al., 2013; Levinson et al., 2017; Marcus, Preszler, \& Zeigler-Hill, 2018). Several centrality indexes (betweenness, closeness, strength) can help determine the core position of nodes. In addition, Jones, Ma, and McNally (2019) argued that traditional centrality indexes may not be very accurate when analyzing cooccurrence disorders. Thus, they proposed bridge centrality (index of bridge symptoms) in a network consisting of different disorders or communities (e.g., depression, anxiety, and substance use) to evaluate the importance of nodes. Bridge centrality includes bridge closeness, bridge betweenness, and bridge strength.

Combinations of EST and NTMD. In the same year, Jones, Heeren, and McNally (2017) extended the NTMD (called the extended NTMD in their paper). The extended NTMD argues that nodes should not be limited to symptoms and may also consist of biological, cognitive, or other individual-level processes, which can lead to a disorder or cause symptoms of a disorder. Some researchers also believe that EST should be not only nested but also networked, which provides support for the idea of combining EST and NTMD in this study. Neal and Neal (2013) argued that the use of network terms to define ecosystem EST not only provides greater theoretical clarity but also conveys a more consistent understanding of Bronfenbrenner's early recognition of the role of social networks in shaping development. Therefore, the limitations of existing research can be solved with the combination of EST and NTMD because of several similarities between the two theories. First, both EST and NTMD emphasize the importance of interactions between variables. The former highlights the interactions of variables in microsystems and variables from different microsystems, and the latter stresses the interactions between different symptoms. Second, since both theories consider interactions from the perspective of a network, there is a self-maintaining effect in the network, which develops and maintains this network (Borsboom, 2017). Therefore, in this study, we combined these two theories to explore the relationships between PSU and its related factors from a network perspective.

\section{Selection of factors related to juveniles' PSU}

Network theory stresses the importance of causal relationships between symptoms, while the extended NTMD proposes that nodes should not be limited to symptoms; they may also consist of biological, cognitive, or other individuallevel processes. Therefore, we encompass PSU symptoms into the network based on NTMD, while we conclude factors related to PSU based on extended NTMD and EST. Jones et al., (2017) reminded researchers that adding nodes to a network with symptoms should have empirical support and caution. Therefore, this study focused on the symptoms of PSU and chose factors related to PSU based on previous research and theoretical rationale, which could demonstrate the causal relationships between variables. Based on previous literature (Billieux, 2012; Busch \& Mccarthy, 2020; Gutiérrez et al., 2016; Park \& Park, 2014), this study classified the antecedents of PSU into individual variables, school environments, and family environments. The reviews by Gutiérrez's et al., (2016) and Billieux's (2012) pathway models of PSU stress the role of impulsivity and control ability on PSU. Elhai, Levine, and Hall's (2019) conceptual frameworks of PSU and anxiety regard the fear of missing out and social isolation as risk factors for PSU. Therefore, self-control, fear of missing out, loneliness, and social anxiety were included as individual variables. In addition, based on previous reviews and the literature, factors related to school environments and family environments were selected. Namely, related PSU factors were categorized into individual variables, school environments, and family environments according to previous comprehensive reviews (Billieux, 2012; Busch \& Mccarthy, 2020; Gutiérrez et al., 2016; Park \& Park, 2014) and ecological system theory (Bronfenbrenner, 1993). The selected factors and related references supporting the relationships between factors and juveniles' PSU are presented in Table 1. For some factors that were selected, no empirical literature has demonstrated the bidirectional relationships between them and juveniles' PSU, and previous literature Busch and Mccarthy (2020) failed to determine which came first. Therefore, we believe that interactions exist between the selected variables and juveniles' PSU. Additionally, although we theoretically believe in the bidirectional interactions within microsystems and interactions between different microsystems based on EST, we need to elaborate on these phenomena more specifically. However, we have specifically illustrated these phenomena in the previous section from the perspective of the spillover effect and peer contagion effect. 
Table 1. Factors used in this research and related references

\begin{tabular}{|c|c|}
\hline Factors selected & References demonstrating that factors affect PSU \\
\hline Self-control $^{+}$ & (Han et al., 2017; Kim et al., 2018; YoungJin \& Kyunghee, 2018) \\
\hline Fear of missing out $(\mathrm{FOMO})^{+}$ & $\begin{array}{l}\text { (Elhai et al., 2016, 2019; Przybylski, Murayama, Dehaan, \& Gladwell, 2013; Wang et al., } \\
\text { 2019; Wolniewicz, Tiamiyu, Weeks, \& Elhai, 2018) }\end{array}$ \\
\hline Social anxiety $^{+}$ & (Elhai, Levine, \& Hall, 2019; Enez Darcin et al., 2016; Hong et al., 2019) \\
\hline Loneliness $^{+}$ & $\begin{array}{l}\text { (Enez Darcin et al., 2016; Esen, Aktas, \& Tuncer, 2013; Karsay et al., 2019; Lapierre, Zhao, } \\
\text { \& Custer, 2019; Mosalanejad, Nikbakht, Abdollahifrad, \& Kalani, 2019; Shen \& Wang, } \\
\text { 2019; Yayan, SunaDağ, \& Düken, 2019) }\end{array}$ \\
\hline Teacher-student relationship * & (Mahapatra, 2019; Yayan et al., 2019) \\
\hline Peer PSU * & Based on the peer contagion hypothesis (Dishion \& Tipsord, 2011) in which peer \\
\hline Peer attitude towards smartphone use * & behavior, attitude, and pressure influence juveniles' behaviors, and the same is true of \\
\hline Peer pressure on smartphone use ${ }^{*}$ & peer PSU, attitudes, and pressure for smartphone use. \\
\hline Friendship quality * & (Wang et al., 2017; Kim et al., 2018) \\
\hline $\begin{array}{l}\text { Parents' drinking and smoking (both } \\
\text { father and mother) }\end{array}$ & Kim et al., (2018) \\
\hline Marital satisfaction & (McDaniel \& Coyne, 2016; McDaniel \& Radesky, 2018) \\
\hline Parents' PSU & (Kim et al., 2018; Xie, Chen, Zhu, \& He, 2019) \\
\hline Technology interference & (McDaniel \& Coyne, 2016; McDaniel \& Radesky, 2018) \\
\hline $\begin{array}{l}\text { Parental mediations (restrictive, active, } \\
\text { and co-use) }\end{array}$ & $\begin{array}{l}\text { (Ko, Choi, Yang, Lee, \&amp; Lee, 2015Ko, Choi, Yang, Lee, \& Lee, 2015; Hwang, Choi, } \\
\text { Yum, \& Jeong, 2017; Lee \& Ogbolu, 2018; Meeus et al., 2019) }\end{array}$ \\
\hline Parents' engagements & $\begin{array}{l}\text { Although no research directly measures the relationship between parent engagement and } \\
\text { PSU, some literature has shown that parental engagement is related to the parent-child } \\
\text { relationship. Therefore, parent engagement should exert influence on PSU. }\end{array}$ \\
\hline Parent-child relationship & (Lee \& Kim, 2018; Xie et al., 2019) \\
\hline $\begin{array}{l}\text { Parent's attitude towards mobile devices } \\
\text { use }\end{array}$ & (Lauricella, Wartella, \& Rideout, 2015; Terras \& Ramsay, 2016) \\
\hline
\end{tabular}

Note. + represents individual variables, ${ }^{*}$ represents variables of school microsystems,

represents variables of family microsystems.

\section{Current study}

This study, guided by ecological system theory and the network theory of mental disorders, uses a network approach to analyze PSU and related factors. The variables in this analysis included PSU symptoms, related factors from family microsystems, individual variables, school microsystems, and mesosystems. From the perspective of an interactive network, we expected to use traditional centrality and bridge centrality to determine the central factors and bridge factors among these influencing factors to provide more specific implications for the future intervention of PSU in children and adolescents. In this research, microsystems and PSU were considered communities mentioned in the analysis of bridge centrality (Jones et al., 2019).

\section{METHODS}

\section{Participants}

In total, 3,442 children and adolescents were investigated from Henan Province, China. After excluding nonresponsive questionnaires, there were 3,248 valid participants (males = 1,638 , average age $=12.27 \pm 2.36$ ), of which 1,520 were students in grade 3 or grade 4 (average age $=9.99 \pm 0.68$ ), 1,219 were students in grade 7 (average age $=13.51 \pm 0.50$ ), and 509 were students in grade 10 (average age $=16.03 \pm$ 0.47 ). The average missing rate for each variable was $1.38 \%$ $\pm 1.55 \%$, and Little's MCAR (missing completely at random) test showed that the missing data were $\operatorname{MCAR}\left(\chi^{2}=\right.$ 9,131.39, $d f=7,297, P<0.001$ ); the EM algorithm (Schafer \& Graham, 2002) was used to process the missing data. The teacher guided the students to complete the questionnaires; if the students did not understand the meaning of sentences, the teacher explained the meaning, and then the students completed the questionnaires independently. In addition, parents (mothers or fathers) completed the corresponding investigation in the parent-teacher conference under the teacher's guidance. Other demographic information (see Table A1 in Appendix), such as gender and parents' occupations, was not included in the network analysis because these variables should not be assumed to exist as causal variables within individuals (Jones et al., 2017).

\section{Measurements}

Problematic smartphone use. A smartphone addiction proneness scale developed for juveniles by Kim et al. (2014) was used to measure PSU. This scale has gained popularity among researchers (Lee \& Ogbolu, 2018; Meeus, Eggermont, \& Beullens, 2019). We used a revised Chinese version scale (Huang et al., 2020), which consists of 16 items and includes 4 dimensions: (1) disturbance of adaptive functions, (2) withdrawal, (3) tolerance, and (4) virtual life orientation. The higher the score is, the higher the tendency for PSU is. In this research, Cronbach's $\alpha$ of the scale was 0.901 , and the 16 items were considered the juveniles' 16 PSU symptoms (as suggested by Huang et al., 2020) when conducting network analysis. 
Factors related to juveniles' PSU. The factors related to juveniles' PSU were categorized into three sections: individual variables, school environment microsystems, and family environment microsystems. Detailed information on each variable is presented in Table 2. Among these factors, only parents' drinking and smoking, marital quality, parents' attitude towards mobile device use, parents' PSU, parental mediation (restrictive, active, and co-use), and technology interference were responded to by parents, while the other variables were responded to by children and adolescents. For each factor, mean scores were used in subsequent network analysis.

\section{Analytical procedure}

First, we used SPSS 20.0 to analyze the data and perform descriptive statistics. Second, we used R 4.4.0 software to perform network analysis. The $\mathrm{R}$ package qgraph (Epskamp, Cramer, Waldorp, Schmittmann, \& Borsboom, 2012) was used to plot the LASSO network graph and to compute the centrality indexes (betweenness, closeness, and strength). The reason we used the LASSO network is that it uses statistical regularization techniques that can limit the number of spurious edges to obtain more interpretable networks (Epskamp \& Fried, 2018). Betweenness refers to the number of times a node lies on the shortest path between any other two nodes; it can identify which nodes play the vital role of a middle station in a network connection. Closeness is defined as how close, in terms of edge distance, a node is on average to all other nodes. Strength is the absolute value of the weights on the edges connected to a node. In addition, we used the Zhangcluster coefficient to reveal the redundancy of each node in the network because the Zhang-cluster coefficient considers the negative edges in a network (Marcus et al., 2018; Zhang \& Horvath, 2005). Third, we used the $\mathrm{R}$ package networktools (Jones, 2017) to analyze bridge symptoms (or factors) reflected by bridge centrality, which includes bridge betweenness (the number of times a node lies on the shortest path between any two nodes from two distinct disorders), bridge closeness (the average distance from a node to all nodes outside of its disorder, with distance based upon the inverse of the edge weights in a weighted network), and bridge strength (a node's sum connectivity with other disorders). In this research, microsystems and PSU can be regarded as different communities (or disorders from the perspective of NTMD). Fourth, we examined the stability of the traditional centrality and bridge centrality of the network because of recent debates that closeness and betweenness may be unstable (Epskamp, Borsboom, \& Fried, 2018; Rodebaugh et al., 2018). The R package bootnet was used to calculate the correlation stability coefficient (CS coefficient), an indicator of centrality stability. Researchers have noted that network centrality is stable when the CS coefficient is greater than 0.25 and 0.50 (Epskamp et al., 2018; Soares, Santiago, Biazevic, et al., 2020). Finally, we performed a redundancy analysis, as suggested by Christensen, Golino, and Silvia (2020). The R package EGAnet was used to perform the redundancy analysis, but our results showed no severe redundancy in the whole network.

\section{Ethics}

This study was approved by the Institutional Review Board (IRB) of the State Key Laboratory of Cognitive Neuroscience and Learning at Beijing Normal University (Ethics approval number: CNL_A_0003_003). We obtained written informed consent from all participants (both children and parents), in line with the code of ethics approved by the Declaration of Helsinki.

\section{RESULTS}

\section{Description of the network}

Figure 1 illustrates that node 15 (loss of control), node 17 (self-control), node 23 (peers attitude towards smartphone use), and node 37 (parent-child relationship) are placed in the center of the network, and they are widely connected with other nodes. This network shows that personal variables, school environments, family environments, and symptoms of PSU interact with one another. The edge between node 34 (parental active mediation) and node 33 (parental restrictive mediation) had the strongest relationship, and the edges between node 2 (excessive use) and node 3 (jeopardize a significant relationship), between node 23 (peer attitude towards smartphone use) and node 24 (peers' pressure for smartphone use), and between node 37 (parentchild relationship) and node 35 (parental co-use mediation) were very intense.

\section{Stability of centrality and bridge centrality}

For traditional centrality, the CS coefficients for strength, closeness, and betweenness were $0.75,0.36$, and 0.36 , respectively (see Fig. A1 in Appendix). For bridge centrality, the CS coefficients for bridge strength, bridge closeness, and bridge betweenness were $0.75,0.44,0.67$, respectively (see Fig. A2 in Appendix). The results showed that both the traditional centrality and the bridge centrality met the required cutoff point suggested by researchers (Epskamp et al., 2018), which means that the network centrality measure was stable in this study.

\section{Centrality of juveniles' networks}

The node centrality results indicated that node 23 (closeness $_{(\text {rank })}=1$ betweenness $_{(\text {rank })}=1$, strength $\left._{(\text {rank })}=1\right)$, node 17 closeness $_{(\text {rank })}=5$, betweenness $\left.{ }_{(\text {rank })}=4, \operatorname{strength}_{(\mathrm{rank})}=2\right)$, node $37 \quad$ closeness $_{(\mathrm{rank})}=4, \quad$ betweenness $_{(\mathrm{rank})}=2$, strength $_{(\text {rank })}=3$ ), and node $15 \quad$ (closeness $_{(\text {rank })}=2$, betweenness $_{(\text {rank })}=1$, strength (rank) $=5$ ) exhibited extremely high centrality. Node 16 had very high strength ( $\operatorname{rank}=4)$, but its betweenness and closeness were relatively low. Therefore, compared to other node centrality indexes (see Fig. 2), the central factors of this network were node 23 (peer 
Table 2. Detailed information on the measurements used in this study

Factors selected Measurements (detailed information)

Fear of missing out (FOMO)

Social anxiety

Loneliness

Self-control

Teacher-student relationship

Peer PSU

Peer attitudes towards smartphone use

Peer pressure for smartphone use

Friendship quality

Parents' drinking and smoking

Marital satisfaction

Parents' PSU

Technology interference
FOMO was measured by the Fear of Missing Out scale (Przybylski et al., 2013), which comprises 10 items (e.g., "I fear others have more rewarding experiences than me"). All items were valued on a 5 -point Likert scale $(1=$ not at all, $5=$ extremely). The Cronbach's $\alpha$ was 0.798 .

The 4 item-social anxiety scale of Wang, Jackson, and Zhangv (2011), revised from Greca and Lopez (1998), was used to measure social anxiety. Higher scores indicate higher social anxiety. Items were scored on a 5 -point Likert scale $(1=$ never, $5=$ always $)(\alpha=0.761)$. An example item: "I get nervous when I meet new people".

Loneliness was measured by the children's loneliness scale developed by Asher, Hymel, and Renshaw (1984). This scale includes 16 items (e.g., "I'm lonely", "I feel alone"), which were valued on a 4 -point Likert scale $(1=$ very inconsistent, $4=$ very consistent). A higher score indicates increased loneliness $(\alpha=0.883)$.

Self-control was measured by the Chinese version self-control scale (Unger, Bi, Xiao, \& Ybarra, 2016), which originates from the Tangney self-control scale (Tangney, Baumeister, \& Boone, 2004). The scale consists of 17 items (e.g., "I have a hard time breaking habits", "I am good at resisting temptation"), in which 9 items were scored reversely on a 4-point Likert scale ( $1=$ very inconsistent, 4 = very consistent). The Cronbach's $\alpha$ was 0.891 , and a higher score indicates higher self-control ability.

The teacher-student relationship scale was adopted from PISA 2015 Assessment and Analytical Framework (OECD, 2017). This scale includes 5 items (e.g., "I get along well with my teacher", "My teacher treats me fairly") ( $\alpha=0.881)$, and the higher the score is, the better the teacherstudent relationship is.

Peer PSU was measured by the partner phubbing scale (Roberts \& David, 2016). This revised scale includes 9 items (e.g., "My friend places his or her cell phone where they can see it when we are together"), and its Cronbach's $\alpha$ was 0.878. A higher score indicates higher peer PSU.

These two factors were revised from peers' attitude on Internet overuse and peer pressure for Internet use (Jin-tao, Chao, Feng-e, Lin-yuan, \& Xiao-yi, 2012; Zhou et al., 2019). Peer attitudes towards smartphone use consisted of 6 items (participants were asked "What is your peers' attitude about the following description?" in 6 aspects, such as excessive reliance on smartphone use and frequent use of smartphone games). Peer pressure for smartphone use contains 7 items (participants were asked "How often did you do the following behaviors under peers' invites or pressures?", such as playing games through the smartphone and prolonging time spent on games through the smartphone). For attitude and pressure, higher scores represent more accepted peer attitudes toward smartphone use and more perceived smartphone use pressure from peers. The former's Cronbach's $\alpha$ was 0.887 , and the latter's Cronbach's $\alpha$ was 0.892 .

Friendship quality was measured by items that were used by Valkenburg and Peter (2007). This measurement includes 4 items (e.g., "I tell my friends about my problems and troubles", "My friends help me to understand myself better"), whose Cronbach's $\alpha$ was 0.849 . A higher score indicates greater friendship quality.

Parents' drinking and smoking behaviors were measured by items revised from YRBS Questionnaire (CDC, 2018). Four items were used in this study to measure fathers' drinking and smoking and mothers' drinking and smoking. Example items include "In the past week, how many days did the child's father drink? (response is from none to 7 days)" or "How many cigarettes did the child's mother consume in the last week? (response is from none to more than 20 per day)".

Marital satisfaction was measured using the quality marriage index (Norton, 1983), which includes 6 items (e.g., "We have a good marriage", "My relationship with my partner makes me happy"), in which items $1-5$ were valued on a 7 -point Likert scale ( $1=$ totally disagree, $7=$ totally agree), and item 6 was valued on a 10 -point Likert scale $(1=$ very unhappy, $10=$ very happy). The Cronbach's $\alpha$ was 0.949 , and a higher score means higher marital quality.

Parents' PSU was evaluated with previous research on problematic smartphone use (Derks \& Bakker, 2014; McDaniel \& Radesky, 2018). We used 3 items (e.g., "I use my smartphone intensively", "When my smartphone blinks to indicate new messages, I cannot resist checking them") to measure parents' PSU. All items were rated on a 4 -point Likert scale $(1=$ very disagree, $4=$ very agree). The Cronbach's $\alpha$ was 0.703

Items measuring technology interference in parent-child relationships were adopted from McDaniel and Radesky (2018). Parents were asked "On a typical day, about how many times do the following devices interrupt a conversation or activity you are engaged in with your child?" including (a) cell phone/smartphone, (b) television, (c) computer, (d) tablet, (e) iPod, and (f)

(continued) 
Table 2. Continued

\begin{tabular}{ll}
\hline Factors selected & Measurements (detailed information)
\end{tabular}

Parental mediation (restrictive, active, and co-use)

Parental engagement

Parent-child relationship

Parents' attitude towards mobile device use video game console. Parents responded to each item on a 7-point Likert scale ranging from none to more than 20 times. The Cronbach's $\alpha$ was 0.731 .

This study revised the parental mediation scale (Hwang \& Jeong, 2015) to form the parental mediation scale on smartphone use for Chinese participants. The revised scale consists of three dimensions: restrictive mediation (e.g., "I set specific rules for using smartphones"), active mediation (e.g., "I explain the disadvantages of overuse of smart devices to my child"), and couse (e.g., "I accompany with my child to use smart devices to study such as finishing homework, etc."). Each dimension includes 3 items, which are rated on a 4-point Likert scale. The Cronbach's $\alpha$ of parental mediation (restrictive, active, and co-use) was $0.797,0.851$, and 0.506 , respectively.

Parental engagement included two aspects: the parents' engagement in the study (revised from TIMSS 2011 Assessment Frameworks (Mullis, Martin, Ruddock, Sullivan, \& Preuschoff, 2011)) and parents' engagement in daily life (revised from PISA 2009 Assessment Framework (OECD, 2009)). The former's example item was "My parents ask me what I am learning in school", and the latter's example item is "My parents spend time with me talking about TV shows, movies, news or books that interest me". The Cronbach's $\alpha$ of the scale was 0.830 .

The social relationship network questionnaire, developed by Furman et al., primarily measures the condition of the relationships between an individual and important-others (e.g., parents, teachers, friends) (Buhrmester \& Furman, 1985) and was revised to form a parent-child relationship scale, which is popular among Chinese researchers (Zhang, Li, Zhang, Lu, \& Wang, 2014). The revised scale includes 23 items (e.g., "Are you satisfied with your relationship with your parents?", "Are you happy when you stay with your parents?") and adopted a 4-point Likert scale $(\alpha=0.902)$. A higher score indicates a better parent-child relationship.

Parents' attitude towards mobile devices use was measured by one item, which stated "What is your attitude toward the use of mobile devices?" This item was valued on a 6-point Likert scale $(1=$ extremely disagree, 6 = very much agree), and a higher score indicates parents with more acceptable attitudes. attitude towards smartphone use), node 17 (self-control), node 15 (loss of control-I15), and node 37 (parent-child relationship). In addition, Fig. 2 reveals the redundancy of each node, and the top 3 redundant nodes were node 21 (teacher-student relationship), node 36 (parental engagement), and node 38 (parents' attitude towards mobile device use).

\section{Bridge centrality of juveniles' PSU-related factors}

Figure 3 presents the bridge centrality indexes of the network. For community PSU, node 15 had the highest bridge centrality (bridge strength ${ }_{(\mathrm{rank})}=13$, bridge betweenness (rank) $=2$, bridge closeness $($ rank $=9$ ) when compared to other nodes of this community. For community person variables, among nodes $17-20$, node 18 exhibited the highest bridge centrality (bridge strength $_{(\text {rank })}=5$, bridge betweenness $($ rank $)=4$, bridge closeness $\left._{(\mathrm{rank})}=3\right)$; however, although nodes $20(\mathrm{rank}=3)$ and 17 (rank = 1) had a very high bridge strength, their other indexes were very low. For the community school microsystem, nodes 23 (bridge strength (rank) $=7$, bridge betweenness $_{(\mathrm{rank})}=1$, bridge closeness (rank) $=1$ ), 24 (bridge strength ${ }_{(\mathrm{rank})}=6$, bridge betweenness ${ }_{(\mathrm{rank})}=8$, bridge closeness $_{(\mathrm{rank})}=2$ ), and 25 (bridge strength ${ }_{(\mathrm{rank})}=4$, bridge betweenness $_{(\mathrm{rank})}=3$, bridge closeness (rank) $=6$ ) all showed considerably high bridge centrality in the whole network. For the community family microsystem, compared to other nodes in this community, node 37 had the highest bridge centrality (bridge strength ${ }_{(\mathrm{rank})}=2$, bridge betweenness ${ }_{(\mathrm{rank})}=7$, bridge closeness (rank) $\left.=4\right)$. Bridge centrality highlighted the importance of node 15 (loss of control-I15), node 18 (fear of missing out), nodes 23-25 (peer attitude towards smartphone use, peer pressure on smartphone use, friendship quality), and node 37 (parent-child relationship), which exerted great impacts on the interactions between different microsystems.

\section{DISCUSSION}

\section{Core symptoms of PSU and related core factors of the PSU network}

This study found that the core factors in the network were peer attitudes towards smartphone use, self-control ability, and the parent-child relationship. In addition, loss of control is was a core symptom (factor) in this network. Many studies have revealed that low self-control exerts both a direct and an indirect role in causing PSU (Cho et al., 2017; Han, Geng, Jou, Gao, \& Yang, 2017; Kim et al., 2016; Lee \& Cho, 2015; Sok, Seong, \& Ryu, 2019; Xiang et al., 2020; Zhang, Tan, \& Lei, 2020), so researchers believe it is an extremely important element of PSU. In addition, self-control both connects individual variables (e.g., loneliness) and is directly or indirectly connected with nonindividual variables, such as those from family environments (Liu, Chui, \& Chung, 2020) and school environments (Humphrey, 1984). For the core role of 


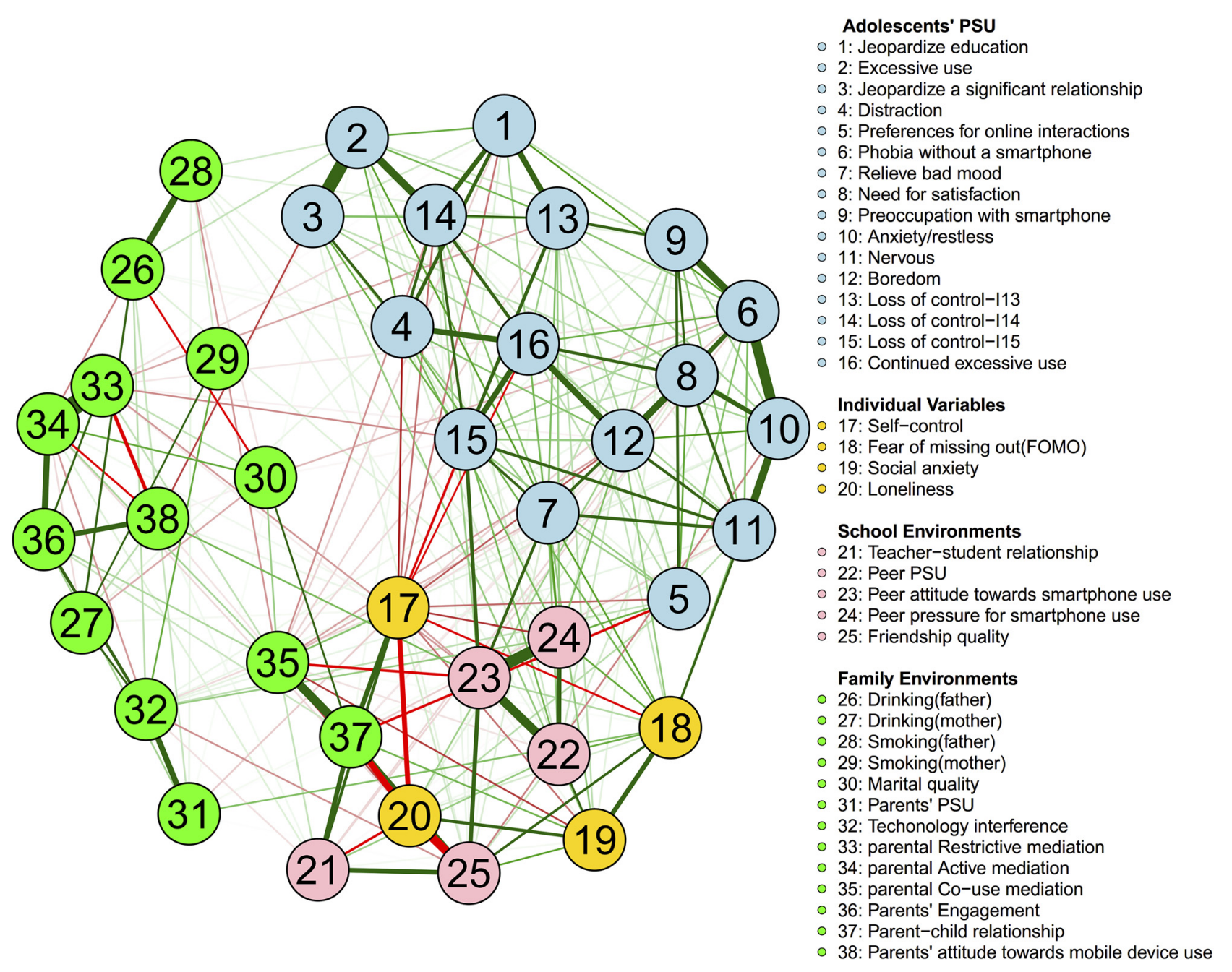

Fig. 1. The GLASSO network of juveniles' PSU, person variables, school and family microsystems

Note: Lines between nodes are called edges or paths, and a thicker edge indicates higher connectivity or intensity between nodes.

peer attitudes towards smartphone use and parent-child relationships, researchers believe that in the process of socialization for children and adolescents, they are more likely to be affected by attitudes or suggestions from peers, not parents, for their development of autonomy and dependence (Zimmer-Gembeck \& Collins, 2003). However, in this process, children's or adolescents' closeness with their parents is still maintained (Kruse \& Walper, 2008; Manago, Brown, Lawley, \& Anderson, 2020). This result may indicate that peer attitudes towards smartphone use and the parent-child relationship are both prominent in this network. For loss of control, our results extended research by Huang et al., (2020) that loss of control was still a core symptom of PSU, even when PSU was placed into a network full of other influencing factors. Therefore, we believe that the three factors and the core symptoms are the central variables connecting the whole network.

Additionally, we must clarify that self-control and loss of control were not redundant in this network. Although they were plausibly similar, they should be different in construction; self-control refers to a kind of ability, while the loss of control is a symptom of PSU. Additionally, our cluster coefficient (an index of redundancy) showed that neither selfcontrol nor loss of control was redundant in this network.

\section{Bridge factors of PSU-related factors}

These findings demonstrate that loss of control, fear of missing out, peer attitudes towards smartphone use, peer pressure for smartphone use, friendship quality, and parentchild relationships had very high bridge symptoms. These results are generally consistent with the results of traditional centrality in terms of factor importance (e.g., they all stress the importance or core role of peer attitudes towards smartphone use, loss of control, and parent-child relationships). What interests us most was that factors concerning peers (peer attitudes toward smartphone use, peer pressure for smartphone use, and friendship quality) were more related to the whole network because they ranked higher in bridge centrality than did factors from other microsystems. We contend that this result was because, at this developmental stage, peers exerted a greater influence on individual 

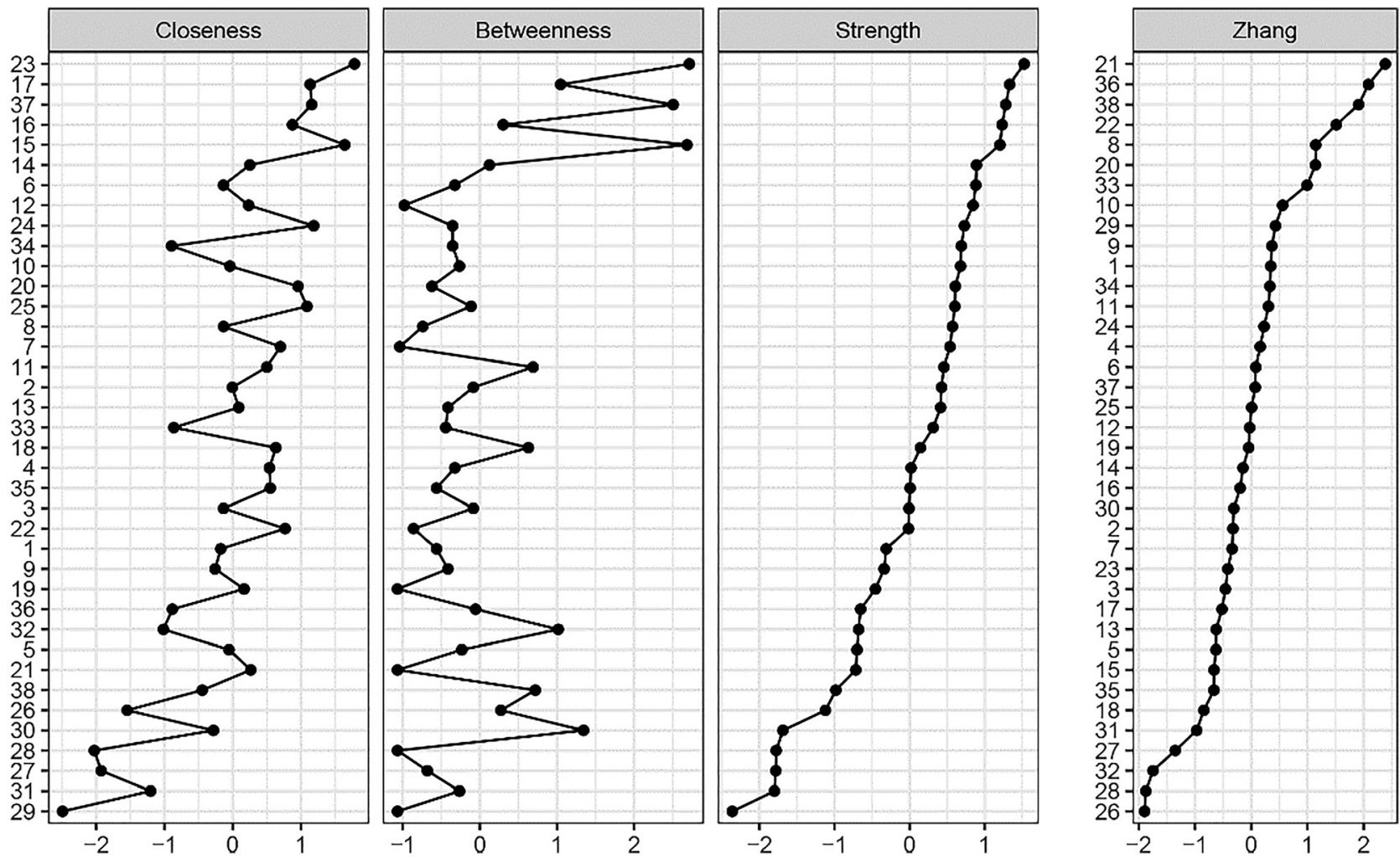

Fig. 2. Centrality indexes and cluster coefficients of juveniles' PSU-related factors

Note. Closeness, betweenness, and strength are the centrality indexes, which were ranked by strength. Zhang is the Zhang clustering coefficient that was ranked by order. The Z-score (not raw score) was used in Fig. 2.

development and individuals' family environments. According to separation-individualization process theory (Mahler, Pine, \& Bergman, 1975), individualization refers to a children's developmental transition from a normal symbiotic period with parents to a new phase as an independent individual. Subsequently, researchers extended this process to adolescence, which was regarded as a second individuation process during that life phase (Kruse \& Walper, 2008). In addition, children spend significant amounts of time with other children, which provides extensive opportunities to influence each other. The same situation exists for adolescents, suggesting that peer influences contribute substantially to socialization from early childhood through the second decade of life and beyond (Hartup, 1999). Consequently, the increasing separation from parents and mounting interactions with peers can explain why peer influence is more vital in juveniles' network of PSU symptoms and factors related to PSU concerning bridge factors.

\section{Implications of this study}

This study explored the influencing factors of juveniles' PSU from the perspective of networked ecological system theory using a network approach, which has both theoretical and social implications. Regarding the theoretical implications, this research is consistent with previous arguments that ecological system theory is networked and synthesizes the network theory of mental disorders and ecological systems theory to explore the interactions between microsystems and PSU using a network analysis method. We hope that our research can adopt the advantages of network theory in the future to promote our extended understanding of EST, and we hope future researchers use a network approach to analyze their studies driven by EST. Regarding clinical implications, network theory and empirical evidence demonstrated that interventions on core factors (core symptoms were used in clinical psychology) effectively reduced the severity of the whole network and benefitted treatment outcomes (Beard et al., 2016; Borsboom, 2017; Borsboom \& Cramer, 2013; Elliott et al., 2020; Levinson et al., 2017; Marcus et al., 2018; Soares, Santiago, Biazevic, et al., 2020; Soares, Santiago, Michel-Crosato, \& Jamieson, 2020). In addition, Jones et al., (2019) illustrated that intervention on bridge factors (bridge symptoms) effectively prevented flow between one disorder and another (e.g., comorbidities). In other words, in this paper, preventing contagion between microsystems may reduce risky interactions between microsystems, which may co-lead to PSU. Consequently, future intervention in juveniles' PSU should focus on core factors and bridge factors (e.g., parents should help cultivate a favorable relationship with children and help them develop their self-control ability). Moreover, teachers and parents should pay attention to juveniles' interactions with peers and guide them to build good relationships with their peers. 

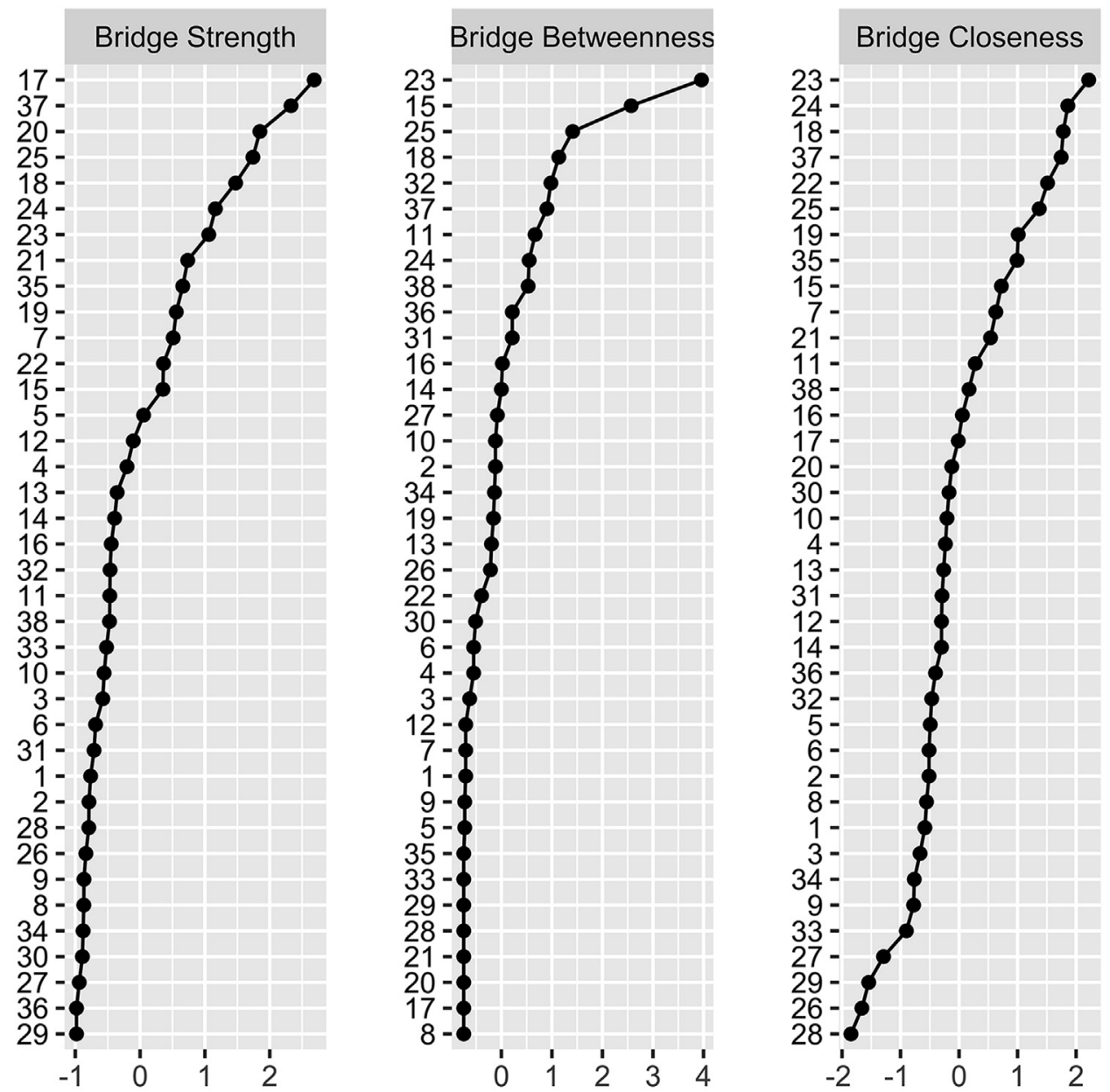

Fig. 3. Bridge centrality indexes of juveniles' PSU and related factors

Note. The bridge centralities were ranked in order, and the Z-score (not raw score) was used in Fig. 3.

\section{Limitations and future directions}

First, these data were collected using a self-reported form from students and parents, which may have resulted in subjective bias and social approval effects. Second, although this research considered many factors, such as individual variables, and school and family microsystems, there are still a host of microsystems, such as community environments, or variables, such as individuals' personalities, that may combine in such interactions of factors in this study. Therefore, future research should include as many variables related to PSU as possible but with caution. Third, although we identified the importance of core and bridge factors based on network theory and empirical studies (Borsboom, 2017; Borsboom \& Cramer, 2013; Jones et al., 2017; Levinson et al., 2017), it is necessary to conduct further experimental or longitudinal design studies to determine whether interventions on these core or critical bridge factors will be more effective than others. Fourth, several researchers have previously argued that there is mixed evidence regarding whether "more central" symptoms are good targets for intervention, which reminds us to interpret our results with caution (Bringmann et al., 2019; Dablander \& Hinne, 2019; Rodebaugh et al., 2018).
Fifth, although we found that the CS coefficient for closeness and betweenness met the required cutoff point in this study with a relatively large sample size, some researchers have noted that the closeness and betweenness centralities are unstable and may lead to inaccurate network estimation (Bringmann et al., 2019). Finally, consistent with the third limitation, the EST in its later development strongly emphasizes that the interactions change over time, and this study fails to broach this subject. Therefore, future research should adopt network analysis based on longitudinal data (Bringmann et al., 2013) or use the recurrence network approach based on time-series data (Hasselman \& Bosman, 2020).

\section{CONCLUSIONS}

The core influencing factors and bridge factors of students' PSU and factors related to PSU included loss of control over smartphone use, self-control, peer attitudes toward smartphone use, and parent-child relationships. The bridge factors included fear of missing out, peer pressure for smartphone use, and friendship quality. Future interventions on juveniles' PSU should focus on these specific and vital factors, 
which may be more effective and inexpensive than current modalities.

Funding sources: This study was funded by the Major Program of the National Social Science Fund of China [Grant Number: 20\&ZD153].

Conflict of interest: The authors declare no conflict of interest.

Authors' contribution: S. H.: study concept and design, analysis and interpretation of data, statistical analysis, writing of the original draft. X. L.: participate in investigation, review and edit the draft, study supervision. Y. L.: participate in investigation. Y. L.: reviewing and edition of the draft. Y. W.: reviewing and edition of the draft, study supervision, obtained funding.

\section{REFERENCES}

Andrade, A. L. M., Kim, D. J., Caricati, V. V., Martins, G. D. G., Kirihara, I. K., Barbugli, B. C., ... De Micheli, D. (2020). Validity and reliability of the Brazilian version of the smartphone addiction scale-short version for university students and adult population. Estudos de Psicologia (Campinas), 37, e190117. https://doi.org/10.1590/1982-0275202037e190117.

Andrade, A. L. M., Scatena, A., Bedendo, A., Enumo, S. R. F., Dellazzana-Zanon, L. L., Prebianchi, H. B., ... de Micheli, D. (2020). Findings on the relationship between Internet addiction and psychological symptoms in Brazilian adults. International Journal of Psychology, 55(6), 941-950. https://doi.org/10.1002/ijop.12670.

Andrade, A. L. M., Scatena, A., Martins, G. D. G., Pinheiro, B. de O., Becker da Silva, A., Enes, C. C., ... Kim, D. J. (2020). Validation of smartphone addiction scale - short version (SASSV) in Brazilian adolescents. Addictive Behaviors, 110, 106540. https://doi.org/10.1016/j.addbeh.2020.106540.

Asher, S. R., Hymel, S., \& Renshaw, P. D. (1984). Loneliness in children. Child Development, 55(4), 1456-1464. https://doi.org/ 10.2307/1130015.

Beard, C., Millner, A. J., Forgeard, M. J. C., Fried, E. I., Hsu, K. J., Treadway, M. T., . . Björgvinsson, T. (2016). Network analysis of depression and anxiety symptom relationships in a psychiatric sample. Psychological Medicine, 46(16), 3359-3369. https://doi.org/10.1017/S0033291716002300.

Billieux, J. (2012). Problematic use of the mobile phone: A literature review and a pathways model. Current Psychiatry Reviews, 8(4), 299-307. https://doi.org/10.2174/157340012803520522.

Billieux, J., Maurage, P., Lopez-Fernandez, O., Kuss, D. J., \& Griffiths, M. D. (2015). Can disordered mobile phone use be considered a behavioral addiction? An update on current evidence and a comprehensive model for future research. Current Addiction Reports, 2(2), 156-162. https://doi.org/10.1007/ s40429-015-0054-y.

Borsboom, D. (2017). A network theory of mental disorders. World Psychiatry, 16(1), 5-13. https://doi.org/10.1002/wps.20375.
Borsboom, D., \& Cramer, A. O. J. (2013). Network analysis: An integrative approach to the structure of psychopathology. Annual Review of Clinical Psychology, 9(1), 91-121. https://doi. org/10.1146/annurev-clinpsy-050212-185608.

Bringmann, L. F., Elmer, T., Epskamp, S., Krause, R. W., Schoch, D., Wichers, M., ... Snippe, E. (2019). What do centrality measures measure in psychological networks? Journal of Abnormal Psychology, July. https://doi.org/10.1037/abn0000446.

Bringmann, L. F., \& Eronen, M. I. (2018). Don't Blame the model: Reconsidering the network approach to psychopathology. Psychological Review, 125(4), 606-615. https://doi.org/10.1037/ rev0000108.

Bringmann, L. F., Vissers, N., Wichers, M., Geschwind, N., Kuppens, P., Peeters, F., ... Tuerlinckx, F. (2013). A network approach to Psychopathology: New insights into clinical longitudinal data. Plos One, 8(4), e60188. https://doi.org/10.1371/ journal.pone.0060188.

Bronfenbrenner, U. (1979). The ecology of human development. Havard University press.

Bronfenbrenner, U. (1993). The Bronfenbrenner ecological systems theory of human development. In R. H. Wozniak \& K. W. Fischer (Eds.), Development in context: Acting and thinking in specific environments (pp. 3-44). Erlbaum.

Buhrmester, D., \& Furman, W. (1985). Children's perceptions of the personal relationships in their social networks. Developmental Psychology, 21(6), 1016-1024. https://doi.org/10.1037/ 0012-1649.21.6.1016.

Busch, P. A., \& Mccarthy, S. (2020). Antecedents and consequences of problematic smartphone use: A systematic literature review of an emerging research area. In Computers in human behavior. Elsevier Ltd. https://doi.org/10.1016/j.chb. 2020.106414.

CDC (Centers for Disease Control and Prevention) (2018). YRBS questionnaire content - 1991-2019. In Youth risk behavior surveillance system (YRBSS). https://www.cdc.gov/ healthyyouth/data/yrbs/pdf/2019/YRBS_questionnaire_ content_1991-2019.pdf.

Choi, J., Choi, O. J., \& Kim, J. H. (2017). Effects of adolescent smartphone addiction on cybersexual delinquency. Social Behavior and Personality, 45(5), 819-831. https://doi.org/10. 2224/sbp.5916.

Cho, H. Y., Kim, D. J., \& Park, J. W. (2017). Stress and adult smartphone addiction: Mediation by self-control, neuroticism, and extraversion. Stress and Health, 33(5), 624-630. https://doi. org/10.1002/smi.2749.

Christensen, A. P., Golino, H., \& Silvia, P. J. (2020). A psychometric network perspective on the validity and validation of personality trait questionnaires. European Journal of Personality, 34(6), 1095-1108. https://doi.org/10.1002/per.2265.

CNNIC. (2019). Statistical reports on internet development in China (pp. 20-23). CNNIC.

Dablander, F., \& Hinne, M. (2019). Node centrality measures are a poor substitute for causal inference. Scientific Reports, 9(1), 1-13. https://doi.org/10.1038/s41598-019-43033-9.

Demirci, K., Akgönül, M., \& Akpinar, A. (2015). Relationship of smartphone use severity with sleep quality, depression, and anxiety in university students. Journal of Behavioral Addictions, 4(2), 85-92. https://doi.org/10.1556/2006.4.2015.010. 
Derks, D., \& Bakker, A. B. (2014). Smartphone use, work-home interference, and burnout: A diary study on the role of recovery. Applied Psychology, 63(3), 411-440. https://doi.org/10.1111/j. 1464-0597.2012.00530.x.

Dishion, T. J., \& Tipsord, J. M. (2011). Peer contagion in child and adolescent social and emotional development. Annual Review of Psychology, 62(1), 189-214. https://doi.org/10.1146/annurev. psych.093008.100412.

Elhai, J. D., Levine, J. C., Dvorak, R. D., \& Hall, B. J. (2016). Fear of missing out, need for touch, anxiety and depression are related to problematic smartphone use. Computers in Human Behavior, 63, 509-516. https://doi.org/10.1016/j.chb.2016.05. 079.

Elhai, J. D., Levine, J. C., \& Hall, B. J. (2019). The relationship between anxiety symptom severity and problematic smartphone use: A review of the literature and conceptual frameworks. Journal of Anxiety Disorders, 62(October 2018), 45-52. https://doi.org/10.1016/j.janxdis.2018.11.005.

Elhai, J. D., Vasquez, J. K., Lustgarten, S. D., Levine, J. C., \& Hall, B. J. (2018). Proneness to boredom mediates relationships between problematic smartphone use with depression and anxiety severity. Social Science Computer Review, 36(6), 707-720. https://doi.org/10.1177/0894439317741087.

Elliott, H., Jones, P. J., \& Schmidt, U. (2020). Central symptoms predict posttreatment outcomes and clinical impairment in anorexia nervosa: A network analysis. Clinical Psychological Science, 8(1), 139-154. https://doi.org/10.1177/ 2167702619865958.

Enez Darcin, A., Kose, S., Noyan, C. O., Nurmedov, S., Yılmaz, O., \& Dilbaz, N. (2016). Smartphone addiction and its relationship with social anxiety and loneliness. Behaviour and Information Technology, 35(7), 520-525. https://doi.org/10.1080/0144929X. 2016.1158319.

Epskamp, S., Borsboom, D., \& Fried, E. I. (2018). Estimating psychological networks and their accuracy: A tutorial paper. Behavior Research Methods, 50(1), 195-212. https://doi.org/10. 3758/s13428-017-0862-1.

Epskamp, S., Cramer, A. O. J., Waldorp, L. J., Schmittmann, V. D., \& Borsboom, D. (2012). Qgraph: Network visualizations of relationships in psychometric data. Journal of Statistical Software, 48. https://doi.org/10.18637/jss.v048.i04.

Epskamp, S., \& Fried, E. I. (2018). A tutorial on regularized partial correlation networks. Psychological Methods, 23(4), 617-634. https://doi.org/10.1037/met0000167.

Esen, B. K., Aktas, E., \& Tuncer, I. (2013). An analysis of university students' internet use in relation to loneliness and social selfefficacy. Procedia - Social and Behavioral Sciences, 84, 15041508. https://doi.org/10.1016/j.sbspro.2013.06.780.

Greca, A. M. L., \& Lopez, N. (1998). Social anxiety among adolescents: Linkages with peer relations and friendships. Journal of Abnormal Child Psychology, 26(2), 83-94. https://doi.org/10. 1023/A:1022684520514.

Gutiérrez, J. D. S., de Fonseca, F. R., \& Rubio, G. (2016). Cell-phone addiction: A review. Frontiers in Psychiatry, 7, 175. https://doi. org/10.3389/fpsyt.2016.00175.

Han, L., Geng, J., Jou, M., Gao, F., \& Yang, H. (2017). Relationship between shyness and mobile phone addiction in Chinese young adults: Mediating roles of self-control and attachment anxiety.
Computers in Human Behavior, 76, 363-371. https://doi.org/10. 1016/j.chb.2017.07.036.

Hartup, W. W. (1999). Constraints on peer Socialization: Let me count ways. Merrill-Palmer Quarterly, 45(1), 172-183. https:// doi.org/10.2307/23093323.

Hasselman, F., \& Bosman, A. M. T. (2020). Studying complex adaptive systems with internal states: A recurrence network approach to the analysis of multivariate time-series data representing self-reports of human experience. Frontiers in Applied Mathematics and Statistics, 6, 1-14. https://doi.org/10.3389/ fams.2020.00009.

Herrero, J., Urueña, A., Torres, A., \& Hidalgo, A. (2017). Smartphone addiction: Psychosocial correlates, risky attitudes, and smartphone harm. Journal of Risk Research, 9877(July), 1-12. https://doi.org/10.1080/13669877.2017.1351472.

Hong, W., Liu, R. D., Oei, T. P., Zhen, R., Jiang, S., \& Sheng, X. (2019). The mediating and moderating roles of social anxiety and relatedness need satisfaction on the relationship between shyness and problematic mobile phone use among adolescents. Computers in Human Behavior, 93, 301-308. https://doi.org/10. 1016/j.chb.2018.12.020.

Horwood, S., \& Anglim, J. (2018). Personality and problematic smartphone use: A facet-level analysis using the five factor model and HEXACO frameworks. Computers in Human Behavior, 85, 349-359. https://doi.org/10.1016/j.chb.2018.04.013.

Huang, S., Lai, X., Xue, Y., Zhang, C., \& Wang, Y. (2020). A network analysis of problematic smartphone use symptoms in a student sample. Journal of Behavioral Addictions, 1-12. https:// doi.org/10.1556/2006.2020.00098.

Humphrey, L. L. (1984). Children's self-control in relation to perceived social environment. Journal of Personality and Social Psychology, 46(1), 178-188. https://doi.org/10.1037/0022-3514. 46.1.178.

Hwang, Y., Choi, I., Yum, J.-Y., \& Jeong, S.-H. (2017). Parental mediation regarding children's smartphone use: Role of protection motivation and parenting style. Cyberpsychology, Behavior, and Social Networking, 20(6), 362-368. https://doi. org/10.1089/cyber.2016.0555.

Hwang, Y., \& Jeong, S.-H. (2015). Predictors of parental mediation regarding children's smartphone use. Cyberpsychology, Behavior, and Social Networking, 18(12), 737-743. https://doi.org/10.1089/ cyber.2015.0286.

Jin-tao, Z., Chao, C., Feng-e, L., Lin-yuan, D., \& Xiao-yi, F. (2012). Perceived peers' internet overuse behavior, attitude on internet overuse, pressures of internet using and college students' internet addiction. Psychological Development and Education, 28(6), 634640. https://doi.org/10.16187/j.cnki.issn1001-4918.2012.06.003.

Johnson, G. M., \& Puplampu, P. (2008). A conceptual framework for understanding the effect of the Internet on child development: The ecological techno-subsystem. Canadian Journal of Learning and Technology, 34, 19-28.

Jones, P. J. (2017). Networktools: Tools for identifying important nodes in networks. Retrieved from http://www.researchgate. net/publication/316279813_networktools_Assorted_Tools_for_ Identifying_Important_Nodes_in_Networks.

Jones, P. J., Heeren, A., \& McNally, R. J. (2017). commentary: A network theory of mental disorders. Frontiers in Psychology, 8, 1305. https://doi.org/10.3389/fpsyg.2017.01305. 
Jones, P. J., Ma, R., \& McNally, R. J. (2019). Bridge centrality: A network approach to understanding comorbidity. Multivariate Behavioral Research, 1, 1-15. https://doi.org/10.1080/00273171. 2019.1614898.

Karsay, K., Schmuck, D., Matthes, J., \& Stevic, A. (2019). Longitudinal effects of excessive smartphone use on stress and loneliness: The moderating role of self-disclosure. Cyberpsychology, Behavior, and Social Networking, 22(11), 706-713. https://doi.org/10.1089/cyber.2019.0255.

Kim, Y., Jeong, J. E., Cho, H., Jung, D. J., Kwak, M., Rho, M. J., ... Choi, I. Y. (2016). Personality factors predicting smartphone addiction predisposition: Behavioral inhibition and activation systems, impulsivity, and self-control. Plos One, 11(8), 1-15. https://doi.org/10.1371/journal.pone.0159788.

Kim, D., Lee, Y., Lee, J., Nam, J. E. K., \& Chung, Y. (2014). Development of Korean smartphone addiction proneness scale for youth. Plos One, 9(5), 1-8. https://doi.org/10.1371/journal. pone.0097920.

Kim, H. J., Min, J. Y., Min, K. B., Lee, T. J., \& Yoo, S. (2018). Relationship among family environment, self-control, friendship quality, and adolescents' smartphone addiction in South Korea: Findings from nationwide data. Plos One, 13(2), 1-13. https://doi.org/10.1371/journal.pone.0190896.

Kim, S. G., Park, J., Kim, H. T., Pan, Z., Lee, Y., \& McIntyre, R. S. (2019). The relationship between smartphone addiction and symptoms of depression, anxiety, and attention-deficit/ hyperactivity in South Korean adolescents. Annals of General Psychiatry, 18(1), 1-8. https://doi.org/10.1186/s12991-0190224-8.

Ko, S. (2012). Viability of social enterprises: The spillover effect. Social Enterprise Journal, 8(3), 251-263. https://doi.org/10. 1108/17508611211280782.

Ko, M., Choi, S., Yang, S., Lee, J., \& Lee, U. (2015). FamiLync: Facilitating participatory parental mediation of adolescents smartphone use. In Proceedings of the 2015 ACM International Joint Conference on Pervasive and Ubiquitous Computing, 867-878. https://doi.org/10.1145/2750858.2804283.

Kruse, J., \& Walper, S. (2008). Types of individuation in relation to parents: Predictors and outcomes. International Journal of Behavioral Development, 32(5), 390-400. https://doi.org/10. 1177/0165025408093657.

Kwak, J. Y., Kim, J. Y., \& Yoon, Y. W. (2018). Effect of parental neglect on smartphone addiction in adolescents in South Korea. Child Abuse and Neglect, 77, 75-84. https://doi.org/10.1016/j. chiabu.2017.12.008.

Kwon, M., Lee, J. Y., Won, W. Y., Park, J. W., Min, J. A., Hahn, C., .. Kim, D. J. (2013). Development and validation of a smartphone addiction scale (SAS). Plos One, 8(2). https://doi. org/10.1371/journal.pone.0056936.

Lapierre, M. A., Zhao, P., \& Custer, B. E. (2019). Short-term longitudinal relationships between smartphone use/dependency and psychological well-being among late adolescents. Journal of Adolescent Health, 65(5), 607-612. https://doi.org/10.1016/j. jadohealth.2019.06.001.

Lauricella, A. R., Wartella, E., \& Rideout, V. J. (2015). Young children's screen time: The complex role of parent and child factors. Journal of Applied Developmental Psychology, 36, 11-17. https://doi.org/10.1016/j.appdev.2014.12.001.
Lee, J., \& Cho, B. (2015). Effects of self-control and school adjustment on smartphone addiction among elementary school students. International Journal of Contents, 11(3), 1-6. https:// doi.org/10.5392/ijoc.2015.11.3.001.

Lee, E. J., \& Kim, H. S. (2018). Gender differences in smartphone addiction behaviors associated with parent-child bonding, parent-child communication, and parental mediation among Korean elementary school students. Journal of Addictions Nursing, 29(4), 244-254. https://doi.org/10.1097/JAN. 0000000000000254.

Lee, E. J., \& Ogbolu, Y. (2018). Does parental control work with smartphone addiction?: A cross-sectional study of children in South Korea. Journal of Addictions Nursing, 29(2), 128-138. https://doi.org/10.1097/JAN.0000000000000222.

Levinson, C. A., Zerwas, S., Calebs, B., Forbush, K., Kordy, H., Watson, H., ... Bulik, C. M. (2017). The core symptoms of bulimia nervosa, anxiety, and depression: A network analysis. Journal of Abnormal Psychology, 126(3), 340-354. https://doi. org/10.1037/abn0000254.

Liu, F., Chui, H., \& Chung, M. C. (2020). The effect of parentadolescent relationship quality on deviant peer affiliation: The mediating role of self-control and friendship quality. Journal of Social and Personal Relationships, 1-23. https://doi.org/10. 1177/0265407520937358.

Mahapatra, S. (2019). Smartphone addiction and associated consequences: Role of loneliness and self-regulation. Behaviour and Information Technology, 38(8), 833-844. https://doi.org/10. 1080/0144929X.2018.1560499.

Mahler, M. S., Pine, F., \& Bergman, A. (1975). The psychological birth of the human infant. Hutchinson \& Co (Publishers) Ltd.

Manago, A. M., Brown, G., Lawley, K. A., \& Anderson, G. (2020). Adolescents' daily face-to-face and computer-mediated communication: Associations with autonomy and closeness to parents and friends. Developmental Psychology, 56(1), 153-164. https://doi.org/10.1037/dev0000851.

Marcus, D. K., Preszler, J., \& Zeigler-Hill, V. (2018). A network of dark personality traits: What lies at the heart of darkness? Journal of Research in Personality, 73, 56-62. https://doi.org/10. 1016/j.jrp.2017.11.003.

McDaniel, B. T., \& Coyne, S. M. (2016). Technology interference in the parenting of young children: Implications for mothers' perceptions of coparenting. Social Science Journal, 53(4), 435443. https://doi.org/10.1016/j.soscij.2016.04.010.

McDaniel, B. T., \& Radesky, J. S. (2018). Technoference: Parent distraction with technology and associations with child behavior problems. Child Development, 89(1), 100-109. https:// doi.org/10.1111/cdev.12822.

Meeus, A., Eggermont, S., \& Beullens, K. (2019). Constantly connected: The role of parental mediation styles and self-regulation in pre-and early adolescents' problematic mobile device use. Human Communication Research, 45(2), 119-147. https://doi. org/10.1093/hcr/hqy015.

Mosalanejad, L., Nikbakht, G., Abdollahifrad, S., \& Kalani, N. (2019). The prevalence of smartphone addiction and its relationship with personality traits, loneliness and daily stress of students in Jahrom University of medical sciences in 2014: A cross-sectional analytical study. Journal of Research in Medical 
and Dental Science, 7(2), 131-136. https://doi.org/10.33880/ ejfm.2020090103.

Mullis, I. V. S., Martin, M. O., Ruddock, G. J., Sullivan, C. Y. O., \& Preuschoff, C. (2011). TIMSS 2011 assessment frameworks. TIMSS \& PIRLS International Study Center Lynch School of Education, Boston College. http://timssandpirls.bc.edu.

Neal, J. W., \& Neal, Z. P. (2013). Nested or networked? Future directions for ecological systems theory. Social Development, 22(4), 722-737. https://doi.org/10.1111/sode.12018.

Norton, R. (1983). Measuring marital quality: A critical look at the dependent variable author(s): Journal of Marriage and the Family, 45(1), 141-151. https://doi.org/10.2307/351302.

OECD. (2009). PISA 2009 Assessment Framework: Key competencies in reading, mathematics and science. In OECD (Ed.), OECD publishing. OECD Publishing. https://doi.org/10.1787/ 9789264062658-en.

OECD. (2017). PISA 2015 assessment and analytical framework: Science, reading, mathematic, financial literacy and collaborative problem solving. In OECD publishing. OECD publishing. https://doi.org/10.1787/9789264281820-en.

Panova, T., \& Carbonell, X. (2018). Is smartphone addiction really an addiction? Journal of Behavioral Addictions, 1-8. https://doi. org/10.1556/2006.7.2018.49.

Park, C., \& Park, Y. R. (2014). The conceptual model on smart phone addiction among early childhood. International Journal of Social Science and Humanity, 4(2), 147-150. https://doi.org/ 10.7763/ijssh.2014.v4.336.

Peng, C. (2017). Effect of negative work-to-family spillover on adolescent externalizing behavior via parental stress and parental involvement. Iowa State University. https://lib.dr. iastate.edu $/ \mathrm{cgi} /$ viewcontent.cgi? article $=6404 \&$ context $=$ etd.

Przybylski, A. K., Murayama, K., Dehaan, C. R., \& Gladwell, V. (2013). Motivational, emotional, and behavioral correlates of fear of missing out. Computers in Human Behavior, 29(4), 1841-1848. https://doi.org/10.1016/j.chb.2013.02.014.

Roberts, J. A., \& David, M. E. (2016). My life has become a major distraction from my cell phone: Partner phubbing and relationship satisfaction among romantic partners. Computers in Human Behavior, 54, 134-141. https://doi.org/10.1016/j.chb. 2015.07.058.

Rodebaugh, T. L., Tonge, N. A., Piccirill, M. L., Fried, E., Horenstein, A., Morrison, A. S., ... Heimberg, R. G. (2018). Does centrality in a cross-sectional network suggest intervention targets for social anxiety disorder? Journal of Consulting and Clinical Psychology, 86(10), 831-844. https://doi.org/10.1037/ ccp0000336.

Schafer, J. L., \& Graham, J. W. (2002). Missing data: Our view of the state of the art. Psychological Methods, 7(2), 147-177. https://doi.org/10.1037/1082-989X.7.2.147.

Sears, M. S., Repetti, R. L., Reynolds, B. M., Robles, T. F., \& Krull, J. L. (2016). Spillover in the home: The effects of family conflict on parents' behavior. Journal of Marriage and Family, 78(1), 127-141. https://doi.org/10.1111/jomf.12265.

Shen, X., \& Wang, J. L. (2019). Loneliness and excessive smartphone use among Chinese college students: Moderated mediation effect of perceived stressed and motivation. Computers in Human Behavior, 95, 31-36. https://doi.org/10.1016/j.chb.2019. 01.012 .
Škařupová, K., Ólafsson, K., \& Blinka, L. (2016). The effect of smartphone use on trends in European adolescents' excessive Internet use. Behaviour and Information Technology, 35(1), 6874. https://doi.org/10.1080/0144929X.2015.1114144.

Soares, G. H., Santiago, P. H. R., Biazevic, M. G. H., Michel-Crosato, E., \& Jamieson, L. (2020). Do network centrality measures predict dental outcomes of Indigenous children over time? International Journal of Paediatric Dentistry, August, 1-13. https://doi.org/10.1111/ipd.12749.

Soares, G. H., Santiago, P. H. R., Michel-Crosato, E., \& Jamieson, L. (2020). The utility of network analysis in the context of Indigenous Australian oral health literacy. Plos One, 15(6), 121. https://doi.org/10.1371/journal.pone.0233972.

Sok, S. R., Seong, M. H., \& Ryu, M. H. (2019). Differences of selfcontrol, daily life stress, and communication skills between smartphone addiction risk group and general group in Korean nursing students. Psychiatric Quarterly, 90(1). https://doi.org/ 10.1007/s11126-018-9596-1.

Tangney, J. P., Baumeister, R. F., \& Boone, A. L. (2004). High selfcontrol predicts good adjustment, less pathology, better grades, and interpersonal success.pdf. Journal of Personality, 2(April 2004), 54.

Terras, M. M., \& Ramsay, J. (2016). Family digital literacy practices and children's mobile phone use. Frontiers in Psychology, 7, 111. https://doi.org/10.3389/fpsyg.2016.01957.

Unger, A., Bi, C., Xiao, Y. Y., \& Ybarra, O. (2016). The revising of the tangney self-control scale for Chinese students. PsyCh Journal, 5(2), 101-116. https://doi.org/10.1002/pchj.128.

Valkenburg, P. M., \& Peter, J. (2007). Preadolescents' and adolescents' online communication and their closeness to friends. Developmental Psychology, 43(2), 267-277. https://doi.org/10. 1037/0012-1649.43.2.267.

Vandell, D. L., Larson, R. W., Mahoney, J. L., \& Watts, T. W. (2015). Children's organized activities. In M. H. Bornstein \& T. Leventhal (Eds.), Handbook of child psychology and developmental science: Ecologicla settings and processes (7th ed., pp. 307-308). John Wiley \& Sons, Inc.

Wang, J. L., Jackson, L. A., \& Zhang, D. J. (2011). The mediator role of self-disclosure and moderator roles of gender and social anxiety in the relationship between Chinese adolescents' online communication and their real-world social relationships. Computers in Human Behavior, 27(6), 2161-2168. https://doi. org/10.1016/j.chb.2011.06.010.

Wang, P., Wang, X., Nie, J., Zeng, P., Liu, K., Wang, J., ... Lei, L. (2019). Envy and problematic smartphone use: The mediating role of FOMO and the moderating role of student-student relationship. Personality and Individual Differences, 146(59), 136-142. https://doi.org/10.1016/j.paid.2019.04.013.

Wang, P., Zhao, M., Wang, X., Xie, X., Wang, Y., \& Lei, L. (2017). Peer relationship and adolescent smartphone addiction: The mediating role of self-esteem and the moderating role of the need to belong. Journal of Behavioral Addictions, 6(4), 708-717. https://doi.org/10.1556/2006.6.2017.079.

Wolniewicz, C. A., Tiamiyu, M. F., Weeks, J. W., \& Elhai, J. D. (2018). Problematic smartphone use and relations with negative affect, fear of missing out, and fear of negative and positive evaluation. Psychiatry Research, 262, 618-623. https://doi.org/ 10.1016/j.psychres.2017.09.058. 
Xiang, M. Q., Lin, L., Wang, Z. R., Li, J., Xu, Z., \& Hu, M. (2020). Sedentary behavior and problematic smartphone use in Chinese adolescents: The moderating role of self-control. Frontiers in Psychology, 10, 1-9. https://doi.org/10.3389/fpsyg. 2019.03032.

Xie, X., Chen, W., Zhu, X., \& He, D. (2019). Parents' phubbing increases Adolescents' Mobile phone addiction: Roles of parentchild attachment, deviant peers, and gender. Children and Youth Services Review, 105, 104426. https://doi.org/10.1016/j. childyouth.2019.104426.

Yayan, E. H., Suna Dağ, Y., \& Düken, M. E. (2019). The effects of technology use on working young loneliness and social relationships. Perspectives in Psychiatric Care, 55(2), 194-200. https://doi.org/10.1111/ppc.12318.

YoungJin, H., \& Kyunghee, L. (2018). Smartphone addiction and school life adjustment among high school students: The mediating effect of self-control. Journal of Psychosocial Nursing and Mental Health Services, 56(11), 28-36. https://doi.org/10. 3928/02793695-20180503-06.

Zhang, B., \& Horvath, S. (2005). A general framework for weighted gene co-expression network analysis. Statistical Applications in
Genetics and Molecular Biology, 4(1). https://doi.org/10.2202/ 1544-6115.1128.

Zhang, X., Li, Y., Zhang, Q., Lu, F., \& Wang, Y. (2014). Smoking and its risk factors in Chinese elementary and middle school students: A nationally representative sample study. Addictive Behaviors, 39(5), 837-841. https://doi.org/10.1016/j.addbeh. 2014.01.025.

Zhang, Y., Tan, D. L., \& Lei, T. T. (2020). Parental attachment and problematic smartphone use among Chinese young adults: A moderated mediation model of interpersonal adaptation and self-control. Journal of Adult Development, 27(1), 49-57. https://doi.org/10.1007/s10804-019-09331-2.

Zhou, N., Ma, S., Li, X., Zhang, J., Liang, Y., Yu, C., ... Fang, X. (2019). Peer contagion processes for problematic internet use among Chinese college students: A process model involving peer pressure and maladaptive cognition. Computers in Human Behavior, 90, 276-283. https://doi.org/10.1016/j.chb.2018.09.016.

Zimmer-Gembeck, M. J., \& Collins, W. A. (2003). Autonomy development during adolescence. In G. R. Adams \& M. D. Berzonsky (Eds.), Blackwell handbook of adolescence (pp. 175176). Blackwell Publishing Ltd. 


\section{APPENDIX}

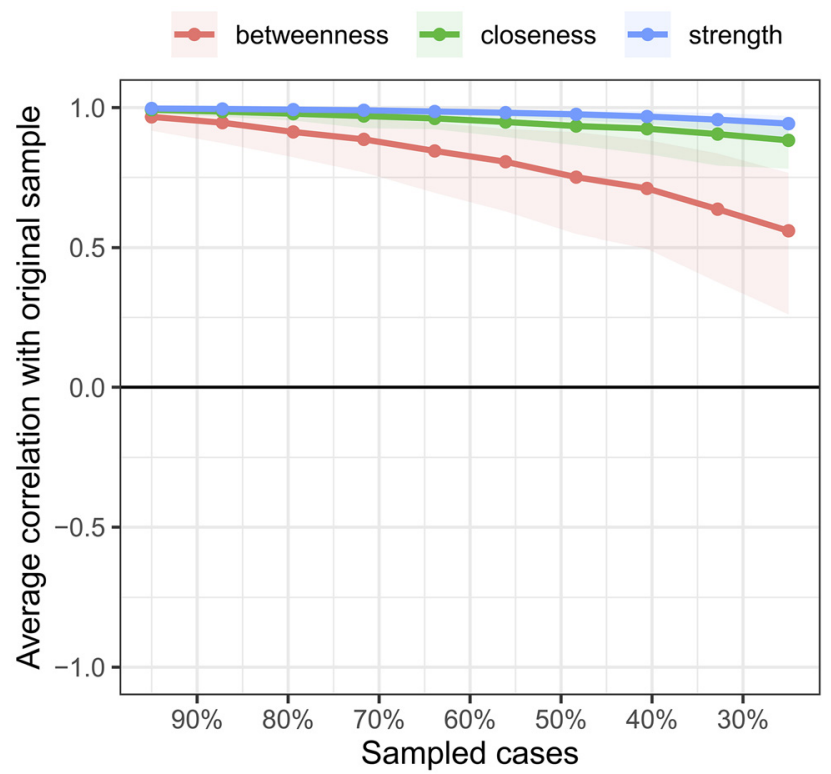

Table A1. Demographic information about juveniles

\begin{tabular}{lcc}
\hline Variables & Groups & Percentage (\%) \\
\hline Residence & City & $47.0 \%$ \\
& Township & $15.4 \%$ \\
Only child & Rural region & $37.7 \%$ \\
& Yes & $88.9 \%$ \\
Mother’s education & No & $11.1 \%$ \\
& $<$ College & $88.99 \%$ \\
Father’s education & $\geqq$ College & $11.01 \%$ \\
& $<$ College & $86.4 \%$ \\
Annual income & $\geqq$ College & $13.6 \%$ \\
& $<50,000 ¥$ & $58.6 \%$ \\
& $50,000 ¥-100,000 ¥$ & $21.9 \%$ \\
& $>100,000 ¥$ & $19.5 \%$ \\
\hline
\end{tabular}

Note. $¥=\mathrm{RMB}$.

Fig. A1. Stability of traditional centrality measures

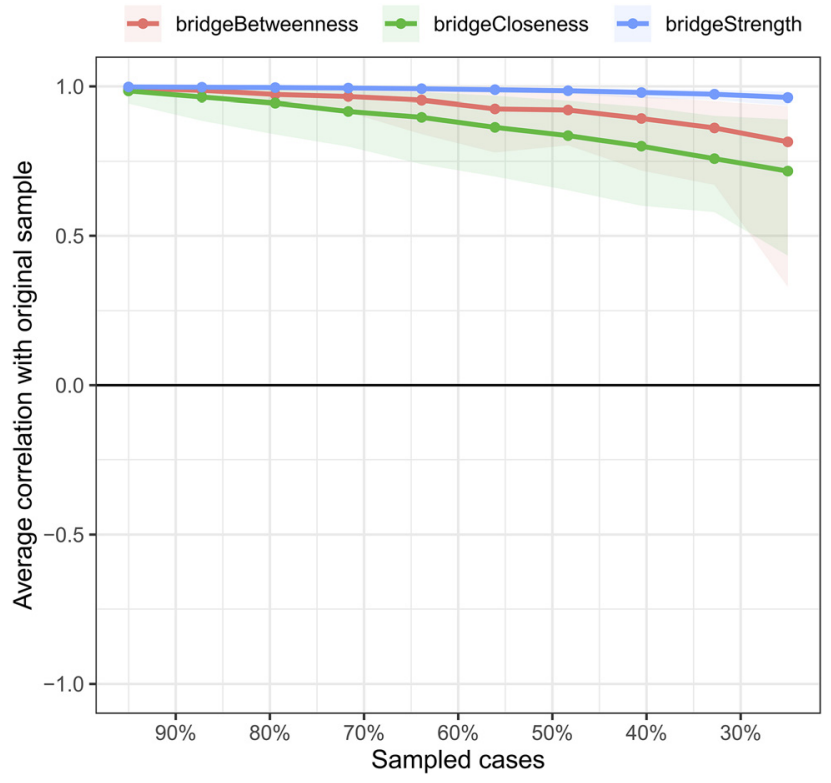

Fig. A2. Stability of bridge centrality measures 